\title{
Gemi Türü Seçimini Etkileyen Faktörlerin Analitik Hiyerarşi Süreci (AHP) Yöntemi Kullanılarak Değerlendirilmesi
}

\author{
Ömer Faruk Görçünª
}

\section{Özet}

Denizyolu taşımacılığı lojistik süreçlerin yanı sıra, küresel tedarik zincirleri için giderek artan bir öneme sahiptir. En az iki liman arasında uzun mesafeli ve diğer taşıma türlerine kıyasla düşük maliyetli taşımacılık faaliyeti yapılmasına olanak sağlayan denizyolu taşımacılığının en temel unsurlarının başında gemiler ve deniz araçları gelmektedir. Bu kapsamda denizyolu taşımacılığı çerçevesinde uygun gemi türünün seçimi son derece kritik bir karar olarak tanımlanabilmektedir. Gemi türü seçimi ile ilgili alınabilecek olası karar alternatifleri çok sayıda faktör tarafından etkilendiği için, söz konusu seçim bir Çok Kriterli Karar Alma problemi (ÇKKV) olarak tanımlanabilir. Bu çalışmada Analitik Hiyerarşi Prosesi (AHP) metodolojisi uluslararası lojistik faaliyetlerde kullanılacak gemilerin türlerine ilişkin seçim süreçlerinde karar alıcılar tarafından karar alma süreçlerinde matematiksel bir model olarak kullanılabilecek yapısal ve sistematik bir çerçeve olarak önerilmektedir.
Anahtar Kelimeler

AHP yöntemi

Gemi Türü Seçimi Lojistik

Denizyolu Taşımacılığ

Makale Hakkında

Geliş Tarihi: 22.11.2018

Kabul Tarihi: 10.06.2020

Doi: $10.18026 /$ cbayarsos.486826

\section{Evaluation of the Criteria Affecting to the Ship Selection Using the Analytic Hierarchy Process (AHP)}

\begin{abstract}
Maritime transportation has an increasing importance for global supply chains. The main element of the maritime transportation that can provide the opportunity to carry out transportation activities between two seaports is the marine vessels. Within this framework, proper ship selection can be defined as an extremely critical decision in the frame of the maritime transportation. Aforementioned selection can be defined as the multi-criteria decision-making problem due to decision alternatives concerning with ship selection are affected by various factors. In this study, the methodology of the Analytic Hierarchy Process is proposed as a systematic and structural frame that can be used as a mathematical model that can be used by decision-makers in the selection process of ships which use in the international logistics activities. This study is based on data that obtained from conducted meetings with experts who are senior executives or owner of maritime transportation companies.
\end{abstract}

Keywords

AHP Method

Ship Selection

Logistics

Maritime Transportation

About Article

Received: 22.11 .2018

Accepted: 10.06 .2020

Doi: $10.18026 /$ cbayarsos.486826

a İletişim Yazarı: omer.gorcun@khas.edu.tr.

b Doç. Dr, Kadir Has Üniversitesi/Kadir Has Caddesi, Cibali Mahallesi, Fatih İstanbul, https://orcid.org/0000-0003-3850-6755. 


\section{Giriş}

Küreselleşme ve endüstri 4.0 gibi süreçlerin etkisi ile lojistik faaliyetlerin en önemli parçalarından birisi olan denizyolu taşımacılığı giderek önemini artırmakta, diğer taşıma türleri ile kıyaslandığında uluslararası ticaretten en yüksek paya sahip olan taşıma türü olma pozisyonunu korumaktadır. Öte yandan lojistik faaliyetlere yönelik gereksinimlerin artmasının yanı sıra giderek değişiklik göstermesi; denizyolu taşımacılığının da yapısal olarak dönüşümünü ve gelişimini zorunlu hale getirmiş, intermodal ve kombine taşımacılığın uluslararası taşımacılıkta daha yüksek düzeyde etkinlik ve verimlilik sağlamasının ve bu taşıma türlerinin tüm taşıma modları arasında kuvvetli bir entegrasyona ihtiyaç duymalarının bir sonucu olarak denizyolu taşımacılığı, diğer taşıma türleri ile daha yüksek düzeyde entegre edilebilir hale gelmiştir.

Öte yandan, denizyolu taşımacılığı her ne kadar yüksek taşıma kapasitesi ve düşük maliyetler ortaya koysa da en büyük dezavantajlarından birisi de yavaş bir taşıma türü olmasıydı. Buna bağlı olarak denizyolu taşımacılığında gözlemlenen bir diğer gelişme gemilerin giderek daha hızlı deniz araçları haline gelmeleri ve geçmişte veremedikleri ulaşım sürelerini günümüzde verebiliyor olmalarıdır. Bu çerçevede uygun gemilerin ve denizyolu araçlarının seçimi ve kullanımı lojistik işletmelere ve denizyolu taşımacılık faaliyeti yürüten işletmelere maliyetlerin kontrol altına alınması, daha rasyonel yatırım maliyetlerine katlanma, operasyonlarda daha yüksek verimliliğin sağlanması gibi stratejik birtakım avantajlar sağlayabilmektedir.

Bunun yanı sıra denizyolu araçlarının seçimine satınalma maliyeti, geminin ekonomik ömrü, fiziksel özellikleri, geminin kabiliyetleri vb. çok fazla sayıda faktör ve değişken etki edebilmekte, karar alıcılar gemi türü seçimi ile ilgili olarak karmaşıklık düzeyi yüksek ve son derece ciddi problemlerle karşı karşıya kalabilmektedir. Etki eden faktörlerin sayısına ve değişkenlik düzeyine bakıldığında gemi türü seçiminin bir Çok Kriterli Karar Verme (ÇKKV) problemi olduğu görülebilmektedir. Bu nedenle gemi türü ile ilgili optimal seçimin sistematik bir çerçeve sağlayacak bir matematiksel modele dayandırılması karar alma süreçlerinde en uygun alternatifin seçilebilmesine olanak sağlayabilecektir.

$\mathrm{Bu}$ çalışma gemi türü seçimi ile ilgili karar alternatiflerinin değerlendirilebilmeleri için metodolojik bir çerçeve olarak Analitik Hiyerarşi Prosesi yaklaşımının kullanılmasını önermektedir. Bu yöntemin seçilmesinin temel nedenlerinin başında seçim kriteri olarak değerlendirilebilecek sayısal nitelikli faktörlerin yanı sıra, sayısal olmayan ve karar alıcıların sözel yargılarına dayanan faktörlerin de değerlendirmeye katılabilmesidir. Entropi, CRITIC, PSI gibi sayısal değerlere odaklanarak faktörlerin ağırlık değerlerini belirleyen objektif yöntemlere ek olarak sadece sayısal performans değerleri ile çözüm sağlayan TOPSIS, MAUT, MOORA vb diğer siralama yöntemlerinden farklı olarak AHP, bu türde sözel yargıların sayısal değerlere dönüştürülerek kıyaslanabilir olmalarına olanak sağlayan bir yöntemdir.

Çalışmanın ilerleyen üçüncü bölümü olan materyal ve metot kısmında AHP yöntemi ve uygulama aşamaları kısaca özetlenmiş, bulgular olarak gösterilen üçüncü bölümde gemi türü seçimine ilişkin elde edilen veriler AHP yöntemi ile analiz edilmiş, dördüncü ve son bölümde ise analizin sonucunda elde edilen çıktılar ve sonuçlar değerlendirilmiştir. 


\section{Literatür ve Önceki Çalışmalar}

Gemi seçimi ile ilgili önceki çalışmalar gözden geçirildiğinde Şener ve Öztürk (2015) Kalite Fonksiyon Dağılımı (QFD) yöntemi kullanarak, gemi seçimlerini analiz etmişler, altı gemi alternatifini değerlendirmişlerdir. Bir başka çalışmada Şener (2016) gemi seçimine etki eden faktörleri DEMATEL yöntemi yardımıyla değerlendirmiş ve yöntemin uygulama adımlarını kullanarak gemi seçimine etki eden seçim kriterlerinin ağırlık değerlerini belirlemiştir.

Cedolin ve Şener (2016) bulanık regresyon ve bulanık hedef programlama yaklaşımlarını kullanarak gemi seçimlerini incelemişlerdir. Kundakçı, Adalı ve Işı (2014) DEMATEL ve ANP yöntemlerini kombine olarak kullanarak, taşımacıllk şirketleri için en uygun gemi alternatifini belirlemeye çalışmışlardır. Yang vd. (2009) belirsizlik altında gemi seçimini incelemişler ve Dempster - Shafer yaklaşımı kullanarak bir denizyolu tanker seçimini değerlendirmişlerdir. Yang, Bonsall ve Wang (2011) çalışmalarında uygun gemi seçimi için Bulanık TOPSİS yöntemini önerdiler.

Uğurlu (2015) ticari gemi seçiminden farklı olarak, denizaşırı gözetim görevlileri için ideal gemi seçimi ile ilgili süreçleri Bulanık Genişletilmiş AHP yaklaşımı çerçevesinde incelemiştir. Yang vd. (2011) çalışmalarında tam belirsizlik ortamında gemi seçimlerini analiz etmişlerdir. Kovačıć ve Mrvıca (2017) Hırvatistan'ın adriyatik denizinde bulunan adaları arasında yapılacak yolcu taşımacılığında kullanılan gemilerin seçimi ile ilgili olarak PROMETHEE ve GIA yöntemlerini birlikte kullanarak en uygun geminin seçimini analiz etmişlerdir. Insignares Verma ve Fuentes (2020) tahrik sistemi ve elektrik jeneratörlerinin edinim maliyeti, yakıt tüketimi ve bakım maliyetleri gibi Teknik parametrelerin yanı sıra, alternatiflerin her biri için yaşam döngüsü maliyet analizi de dikkate alarak petrol tankerlerinin seçimini değerlendirmişlerdir. Xie vd. (2008) petrol tankerlerinin seçimine ilişkin olarak çok kriterli sentez yaklaşımını kullanarak seçim süreçlerini değerlendirmişlerdir.

Literatürde yer alan gemi seçimine ilişkin çalışmalar genel olarak değerlendirildiğinde, çalışmaların gemi alternatiflerini değerlendirmek üzere gerçekleştirilen çalışmalar olduğu, bu çalışmalarda çoğunlukla tanker türü denizyolu araçlarının seçimi ile ilgili süreçlerin farklı çok kriterli karar verme yaklaşımları kullanılarak incelendiği görülmektedir. Temel olarak çalışmaların neredeyse tamamında tek bir gemi sınıfına ait gemi alternatiflerinin karşılaştırıldığı, farklı gemi türlerinin analize dahil edilmediği görülmektedir. Literatürde saptanan eksikliklerin başında farklı gemi türlerinin karşılaştırıldığı bir çalışmaya rastlanılmamış olması gelmektedir.

Öte yandan, kuruyük, kargo gemilerinin seçimine ilişkin çalışmaları son derece az olmakla birlikte konteyner ve Ro-Ro tipi gemilerin seçimi ile ilgili çalışmalara rastlanılmamıştır. Buna paralel olarak, araştırmaların çok büyük bir bölümü belirsizlik ortamında gerçekleşen seçimlere odaklanmış, yöntem olarak farklı yaklaşımlar kullanılmakla birlikte, bunların yine önemli bir kısmı bulanık yaklaşımlardan oluşmaktadır. Buna karşılık gemi seçimleri ile ilgili olarak belirsizlik durumları son derece sınırlıdır. Aynı zamanda seçim kriterleri ile ilgili gerçek sayısal değerler bulmak bütünyle mümkündür. Dolayısıyla gemi seçimlerinin karar vericilerin yargılarına ek olarak gerçek sayısal değerler ile analiz edilmesi daha gerçekçi sonuçlar verebilir. Bu kapsamda bu çalışma literatürde saptanan boşukların giderilmesine katkı sağlamak amacıyla literatüre üç temek katkı sağlama potansiyeline sahiptir. İlk olarak, aynı türden gemilerin değil, gemi türlerinin kıyasladığı bir çalışma olması ile birlikte gemi türlerinin seçimi için karar vericilere metodolojik bir çerçeve önermektedir. İkinci olarak, karar 
vericilerin yargılarına odaklanmakta ve bunları gemi seçim süreçlerini değerlendirmek üzere bilimsel bir perspektifte incelemektedir. Üçüncü olarak, söz konusu çalışma ve gemi türü seçimi ile ilgili önerilen model geliştirilebilir bir niteliğe sahiptir. Bu perspektifte gelecekteki çalışmalarda farklı sıralama ve performans yöntemleri ile entegre edilebilir aynı zamanda gelecekte meydana gelebilecek değişikliklere paralel olarak yeni kriterler ve karar alternatifleri değerlendirme sürecine dahil edilebilir.

\section{Yöntem}

Lojistik ve taşımacılık faaliyetlerinde kullanılacak gemi türünün seçimi ile ilgili olarak Analitik Hiyerarşi Prosesi yöntemi seçilmiştir. Analitik Hiyerarşi Prosesi (AHP), ilk olarak 1968 yılında Myers ve Alpert (1968) tarafından ortaya konmuş matematiksel bir yaklaşımdır. Ancak bu yöntem 1970'li yıllarda Thomas L. Saaty (1977) tarafından geliştirilerek bir Çok Kriterli Kararalma yöntemlerinden birisi haline gelmiştir. Sayısal ölçekte tanımlanan faktör karşılaştırmalarına ek olarak, sözel nitelikli uzman görüş ve yargılarının değerlendirme sürecine dahil edilebilmesine olanak sağlayan bir yöntemdir.

Söz konusu yöntem sayısal olmayan yargıların sayısal ölçeğe dönüştürülebilmesi için Saaty tarafından ortaya konulan 1-9 ölçeğini kullanmakta, her bir faktörün diğerlerine göre önem derecesi sayısal ölçekte gösterilebilmektedir. Aynı zamanda AHP metodu karar verme sürecine etki eden tüm faktörlerin sahip oldukları göreli önem dereceleri çerçevesinde hiyerarşik olarak sıralanmasına da olanak verebilmektedir. Dolayısıyla AHP Yöntemi uygulanarak son derece karmaşık niteliğe sahip karar alma problemleri kolay bir biçimde çözümlenebilmektedir. AHP yöntemi altı aşamalı olarak uygulanan bir yaklaşımdır.

Uygulama olarak, birinci aşamada karar verme problemi ile çalışmanın temel amacı belirlenmektedir. İkinci aşamada faktörler arası karşılaştırma yapabilmek üzere ikili karşılaştırma matrisleri oluşturulmaktadır. Üçüncü aşamada seçim sürecine etki eden faktörlerin önem dereceleri hesaplanmakta, dördüncü aşamada ise değerlendirme sürecinde ele alınan kriterler ile karar noktalarının kendi aralarında tutarlı olup olmadıkları belirlenmektedir. Beşinci aşamada her bir seçim kriterinin karar noktalarına göre önem dereceleri hesaplanırken, altıncı ve son adımda nihai dağılımlar belirlenmekte ve elde edilen sonuçlar yorumlanmaktadır.

Adım-1 Problemin ve Amacın Tanımlanması: AHP yötemi çerçevesinde problemin etkin bir biçimde çözülebilmesi için problemin ve ulaşılmak istenen amacın tanımlanması son derece önem arz eden bir konudur. Bu süreçte öncelikli olarak ulaşılmak istenen amaç net bir biçimde belirlenmekte, bu amaca ulaşılmasında pozitif ya da negatif açıdan etkili olabilecek tüm seçim kriterleri ve olası karar seçenekleri belirlenmektedir. Söz konusu faktörlerin belirlenmesi uzmanlardan oluşan bir kurul ile birlikte yapılması gereken bir süreçtir. Dolayısıyla çalışmanın başında araştırmacılardan beklenen; üye sayısı 5 ila 7 arasında olabilecek bir uzmanlar kurulu, diğer adıyla çalışma grubu oluşturulmasıdır. Çalışma grubunun belirli zamanlarda toplanarak konu ile ilgili beyin fırtınaları çerçevesinde ulaşılmak istenen amaç ile bu amaca ulaşılmasına etki eden olası tüm karar alternatifleri ve seçim kriterlerini değerlendirmesi ve toplantıların sonucunda bunları net bir biçimde tanımlamış olması gerekmektedir. Uzmanlar kurulu tarafından belirlenen faktörler ile bunlar arasındaki ilişkilerin bir hiyerarşik model olarak yapılandırılması ve gösterilmesi gerekmektedir. 


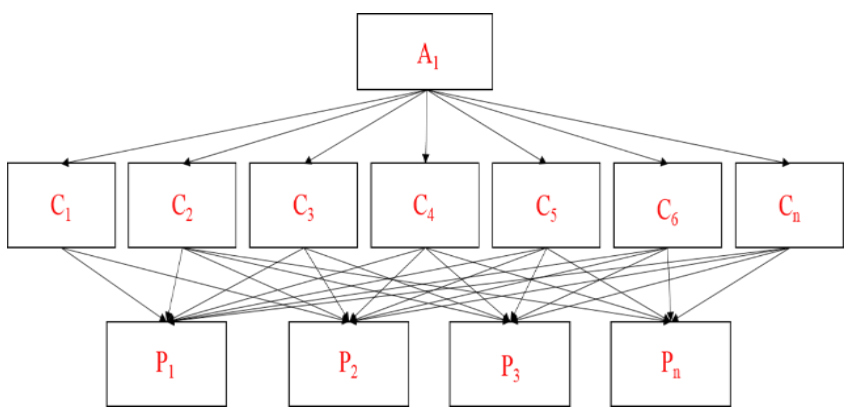

Şekil 1. AHP hiyerarşik modeli

Karar alternatifleri ve seçim kriterleri belirlenirken uzmanlar kurulu m sayıda karar noktası ve $\mathrm{n}$ sayıda seçim kriteri belirleyebilmektedir. Bu konuda dikkat edilmesi gereken temel husus; sürece etki eden tüm faktörlerin ve değişkenlerin mümkün olduğunca dışarıda bırakılmaması, bütüncül bir yaklaşım çerçevesinde tüm faktörlerin değerlendirme sürecine dahil edilmeleridir. Öte yandan bütün faktörlerin sürece dahil olacak tüm karar alıcılar tarafından aynı şekilde algılanması açısından net ve açık bir biçimde tanımlanmış olması yöntemin tutarlılığı ve başarısı açısından son derece önem arz eden bir durumdur.

Adım-2 Karşılaştırma Matrislerinin Oluşturulması: yöntemin ikinci aşamasında faktörler arasında karşılaştırma yapabilmek üzere ikili karşılaştırma matrisleri oluşturulmaktadır. İkili karşılaştırma matrisleri oluşturmak üzere, uzmanlar kurulunca belirlenmiş karar alternatifleri ve seçim kriterleri dikkate alınarak, Saaty'nin 1-9 ölçeği çerçevesinde hazırlanan ikili karşılaştırma soruları karar alıcılara yöneltilmekte, her bir karşılaştırma için elde edilen cevapların geometrik ortalamaları alınarak karar matrisinde yer alan her bir eleman için sayısal değer belirlenmektedir.

Tablo 1. İkili Karşılaştırma Ölçeği

\begin{tabular}{lll}
\hline Skor & \multicolumn{1}{c}{ Tanım } & \multicolumn{1}{c}{ Açıklama } \\
\hline 1 & Eşit Önemli & i ve j eşit derecede önemli \\
3 & Çok Az Önemli & i j'den çok az önemli \\
5 & Kuvvetli Derecede Önemli & i, j'den kuvvetli derecede önemli \\
7 & Çok Kuvvetli Derecede Önemli & i, j'den çok kuvvetli derecede önemli \\
9 & Mutlak Önemli & i, j'den mutlak önemli \\
$2,4,6,8$ & Ara Değerler & \\
Tersleri & Tersi Karşılaştırmalar & \\
\hline
\end{tabular}

Kaynak: Finan, J., ve Hurley, W. (1999).

Karar matrislerinin oluşturulması sürecinde elde edilen verilerin anlamlı ve tutarlı olabilmesi için ikili karşılaştırma sorularının yöneltileceği karar alıcıların da uzmanlar kurulu üyeleri gibi söz konusu alanda uzman olmaları önem arz etmektedir. Bu nedenle soruların yöneltileceği 
karar alıcıların da araştırmacı tarafından belirlenen bu perspektifte seçilmeleri gerekmektedir. Seçilen karar alıcılara ikili karşılaştırma soruları yöneltildikten sonra elde edilen cevapların geometrik ortalamaları alınarak matris elemanlarının sayısal değerleri belirlenmekte ve karar matrisi aşağıdaki gibi gösterilebilmektedir.

$$
A=\left[\begin{array}{cccc}
a_{11} & a_{12} & \ldots & a_{1 n} \\
a_{21} & a_{22} & \ldots & a_{2 n} \\
\cdot & & & \cdot \\
\cdot & & & \cdot \\
\cdot & & & \cdot \\
a_{n 1} & a_{n 2} & \ldots & a_{n n}
\end{array}\right]
$$

Yukarıda gösterilen A matrisi nxn boyutlu bir kare matris olarak tanımlanabilir. Matriste yer alan her bir karşılaştırma dikkate alındığında faktörlerin kendileri ile karşılaştırıldığı elemanlar 1 değerini almaktadır. Dolayısıyla matrisin her bir elemanı bir faktörün bir diğer faktörle ve kendisi ile karşılaştırılma değerini göstermektedir. Öte yandan bir i faktörü j faktörü ile kıyaslandığında alacağı değerin tersi j faktörünün i faktörüne göre önem derecesini göstermektedir (Taşkın ve Eren, 2016).

$$
a_{j i}=\frac{1}{a_{i j}}
$$

Eşitlik 2 de gösterildiği gibi, bir i faktörü j faktörüne göre önem derecesi mutlak önemli ve 9 değerini alıyor ise, $j$ faktörünün $i$ faktörüne göre önem derecesi de 1/9 olarak belirlenebilmektedir. Karar matrisleri oluşturularak, bütün karşılaştırma değerleri matrislere işlendikten sonra, ikinci aşama sonlandırılarak, yöntemin üçüncü aşamasına geçilebilmektedir.

Adım-3 Faktörlerin Önem Dağılımlarının Belirlenmesi: Karar matrisleri yöntemde başlangıç adımı olarak değerlendirilmekte ve matrislerde yer alan elemanlar kıyaslanabilme imkânına sahip olmayabilmektedir. Bunun temel nedeni; her bir faktörün farklı sayısal değerler ile gösterilebilmesi ve bunların kıyaslanabilir olması için ortak bir değere dönüştürülmeleri gerekliliğidir. Bu kapsamda gerçekleştirilen ortak ve kıyaslanabilir değerlere dönüştürme işlemlerine normalizasyon işlemi adı verilmektedir. Bu işlem sonucunda $\mathrm{n}$ sayıda $\mathrm{b}$ vektörü oluşturulmakta, b vektörünün elemanları C matrisi olarak tanımlanan normalize matrisi meydana getirmektedir. Uygulamada A matrisinde yer alan her bir matris elemanı kendi sütun toplamına bölünmektedir (3).

$$
b_{j i}=\frac{a_{i j}}{\sum_{i=1}^{n} a_{i j}}
$$

Eşitlik 2 kullanılarak, A matrisinin her bir sütununda yer alan elemanların normalize edildiği b vektörü aşağıdaki gibi gösterilebilir. Her bir b vektörünün eleman değerleri toplamı 1'e eşit olmak zorundadir.

$$
b_{i}=\left[\begin{array}{c}
b_{11} \\
b_{21} \\
\cdot \\
\cdot \\
\cdot \\
b_{n 1}
\end{array}\right]
$$

Değerlendirilen faktörlerin sayısı kadar b vektörü bir araya getirilerek normalize matris olarak adlandırılan C matrisi elde edilmektedir. 


$$
C=\left[\begin{array}{cccc}
c_{11} & c_{12} & \ldots & c_{1 n} \\
c_{21} & c_{22} & \ldots & c_{2 n} \\
\cdot & & & \cdot \\
\cdot & & & \cdot \\
\cdot & & & \cdot \\
c_{n 1} & c_{n 2} & \ldots & c_{n n}
\end{array}\right]
$$

C matrisinde yer alan elemanların satır aritmetik ortalaması alınarak, her bir faktörün için önem derecesi yüzde cinsinden belirlenebilmektedir (6).

$$
w_{i}=\frac{\sum_{j=1}^{n} c_{i j}}{n}
$$

Her bir satır için aritmetik ortalama hesaplanarak her bir faktör için önem derecesi belirlenirken elde edilen değer öncelik vektörü olarak tanımlanan w vektörü olarak gösterilir.

$$
w=\left[\begin{array}{c}
w_{1} \\
w_{2} \\
\cdot \\
\cdot \\
\cdot \\
w_{n}
\end{array}\right]
$$

Adım-4 Tutarlılık Analizi: Değerlendirme ve analizlerin uygulanabilir ve kabul edilebilir sonuçlar verebilmesi için kendi içerisinde tutarlılığa sahip olması gerekmektedir. Bu nedenle gerçekleştirilen değerlendirmeler için tutarlılık analizi yapılmalıdır. Tutarlılık analizi yapmak için öncelikle D matrisi olarak adlandırılan matrisin oluşturulması gerekli olmaktadır. D matrisini oluşturmak üzere A matrisinin elemanları ile öncelik vektörü olarak tanımlanan w vektörünün elemanları ayrı ayrı çarpılmaktadır. Bu çarpım sonucunda aşağıda gösterilen D matrisi elde edilir.

$$
D=\left[\begin{array}{ccc}
a_{11} & \ldots & a_{1 n} \\
a_{21} & \ldots & a_{2 n} \\
\cdot & & \cdot \\
\cdot & & \cdot \\
\cdot & & \cdot \\
a_{n 1} & \ldots & a_{n n}
\end{array}\right] x\left[\begin{array}{c}
w_{11} \\
w_{21} \\
\cdot \\
\cdot \\
\cdot \\
w_{n}
\end{array}\right]
$$

D matrisinin her bir elamanın w vektör elemanına bölümünden her bir faktör için temel değer olarak tanımlanan E değerine ulaşılabilmektedir.

$$
E_{i}=\frac{d_{i}}{w_{i}} \quad(i=1,2, \ldots, n)
$$

Her bir satır için E değerleri hesaplandıktan sonra, E değerlerinin aritmetik ortalaması karşılaştırma için kullanılacak $\lambda$ mak değerini vermektedir.

$$
\lambda_{\text {mak }}=\frac{\sum_{i=1}^{n} E_{i}}{n}
$$

$\lambda_{\text {mak }}$ değeri hesaplandıktan sonra, CI olarak gösterilen tutarlılık göstergesi aşağıdaki eşitlik 11 yardımı ile hesaplanabilir.

$$
C I=\frac{\lambda_{m a k}-n}{n-1}
$$

Son olarak CI değeri Tablo-2 de gösterilen değerler (Alonso, 2006) dikkate alınarak belirlenen RI değerine bölünerek karşılaştırmada nihai olarak kullanılacak $C R$ değerine ulaşılabilmektedir. CR değeri tutarlılık göstergesi olarak da adlandırılabilmektedir.

$$
C R=\frac{C I}{R I}
$$


Tablo 2: Rassallık Göstergeleri

\begin{tabular}{llllllll}
\hline $\mathrm{n}$ & $\mathrm{RI}$ & $\mathrm{n}$ & $\mathrm{RI}$ & $\mathrm{n}$ & $\mathrm{RI}$ & $\mathrm{n}$ & $\mathrm{RI}$ \\
\hline 1 & 0 & 4 & 0,90 & 7 & 1,32 & 10 & 1,49 \\
2 & 0 & 5 & 1,12 & 8 & 1,41 & 11 & 1,51 \\
3 & 0,58 & 6 & 1,24 & 9 & 1,45 & 12 & 1,48 \\
\hline
\end{tabular}

Elde edilen CR değeri \%10 $(0,10)$ değerinin altında ise değerlendirme tutarlı olarak kabul edilmekte, söz konusu değer \%10'un üzerinde ise tutarsız olarak değerlendirilip, birinci aşamaya geri dönülerek, analizin gözden geçirilmesi gerekmektedir.

Adım-5 Faktörlerin Önem Değerinin Hesaplanması: Beşinci aşamada değerlendirmeye alınan her bir karar alternatifi için yüzde dağılımı hesaplanmaktadır. Bu değerler aynı zamanda her bir karar alternatifinin diğer alternatiflere göre yüzde cinsinden önem değerini göstermektedir. Bu aşamada seçim kriterleri için gerçekleştirilen hesaplamalar her bir karar alternatifi için seçim kriteri sayısınca tekrarlanmakta, bu perspektifte mxm boyutlu n kadar matris elde edilmektedir. Karar alternatifleri için gerçekleştirilecek önceki dört adım sonucunda s sütun vektörleri elde edilmekte, bu vektörler her bir seçim kriteri çerçevesinde karar alternatiflerinin önem değerini tanımlamaktadır.

$$
s=\left[\begin{array}{c}
s_{1} \\
s_{2} \\
\cdot \\
\cdot \\
\cdot \\
s_{m}
\end{array}\right]
$$

$S$ vektörleri her bir seçim kriteri için ele alınan n sayıda karar alternatifinin göreli önem değerini gösterirken, bu vektörlerin toplamı $\mathrm{K}$ matrisi olarak adlandırılan bütün karar alternatiflerinin birlikte gösterildiği matrisi meydana getirmektedir.

Adım-6 Sonuç Dağılımlarının Belirlenmesi: Son aşamada bütün s vektörleri bir araya getirilerek K matrisi elde edilmektedir. Yukarıda bahsedildiği gibi K matrisi mxn boyutlu bir matris olup, bütün karar alternatiflerinin önem derecelerini göstermektedir.

$$
K=\left[\begin{array}{cccc}
s_{11} & s_{12} & \ldots & s_{1 n} \\
s_{21} & s_{22} & \ldots & s_{2 n} \\
\cdot & & & \cdot \\
\cdot & & & \cdot \\
\cdot & & & \cdot \\
s_{m 1} & s_{m 2} & \ldots & s_{m n}
\end{array}\right]
$$

$\mathrm{K}$ matrisi elde edildikten sonra, nihai olarak seçim kriterlerine ilişkin daha önce elde edilen öncelik vektörü ile çarpılarak, her bir karar noktasının diğer alternatiflere kıyasla öncelik değeri yüzde cinsinden belirlenebilmektedir.

$$
L=\left[\begin{array}{cccc}
s_{11} & s_{12} & \ldots & s_{1 n} \\
s_{21} & s_{22} & \ldots & s_{2 n} \\
\cdot & & & \cdot \\
\cdot & & & \cdot \\
\cdot & & & \cdot \\
s_{m 1} & s_{m 2} & \ldots & s_{m n}
\end{array}\right] x\left[\begin{array}{c}
w_{1} \\
w_{2} \\
\cdot \\
\cdot \\
\cdot \\
w_{n}
\end{array}\right]=\left[\begin{array}{c}
l_{1} \\
l_{2} \\
\cdot \\
\cdot \\
\cdot \\
l_{m}
\end{array}\right]
$$




\section{Gemi Türünün AHP Yöntemi ile Seçilmesi}

Bu çalışmada gemi türü seçimi ile ilgili karar problemi seçimi etkileyen faktörler ışığında AHP yönteminin uygulama adımları takip edilerek incelenmiştir. Araştırma verilerinin elde edilebilmesi için yoğun bir saha çalışmasının yapılması zorunlu olmuş, bu kapsamda araştırmanın önemli bir kısmı saha çalışmalarına ayrılmıştır. Nihai olarak uygulamada kullanılacak veriler saha çalışmaları ve sektörde yer alan işletme ve bu işletmelerin yöneticileri ile gerçekleştirilen toplantılar ve arama çalıştaylarıyla elde edilmiştir.

\section{Gemi Türü Seçimiinde Analitik Hiyerarşi Süreci (AHP) Uygulama Adımları}

Gemi seçimine ilişkin karar probleminin çözümü için önerilen AHP yöntemi kullanılarak gerçekleştirilen çalışma daha önce de bahsedildiği gibi altı uygulama adımı takip edilerek çözüme ulaşılabilmektedir.

Adım-1 Problemin ve Amacın Tanımlanması: Çalışmanın birinci aşamasında problemin ve araştırma sonucu ulaşılmaya çalışılan amacın belirlenebilmesi için uzmanlar kurulu olarak adlandırılan bir çalışma grubu oluşturulmuştur. Bu çalışma grubuna denizcilik sektöründe en az on yıl üst düzey yönetici olarak çalışmış yöneticiler, işletme sahipleri ya da mesleki kuruluş temsilcileri üye olarak seçilmiştir. Bu kapsamda uzmanlar kurulu 7 uzman üyeden oluşacak şekilde belirlenmiştir. Uzmanlar kurulu ile gerçekleştirilen toplantılarda gemi türü seçimine ilişkin seçim kriterleri ve karar alternatifleri belirlenmiştir. Bütün kriterler C1 den Cn e kadar ve karar noktaları ise P1 den Pn e kadar ayrı ayrı kodlanmıştır.

Tablo 3: Gemi Türü Seçim Kriterleri ve Karar Noktaları.

\begin{tabular}{llll}
\hline Gemi Seçim Kriterleri & \multicolumn{2}{l}{ Karar Noktaları } \\
\hline Kod & Seçim Kriteri & Kod & Alternatif \\
\hline C1 & Geminin Hızı & P1 & Tanker \\
C2 & Geminin Taşıma Kapasitesi & P2 & Konteyner \\
C3 & Geminin Güvenlik Düzeyi & P3 & Kuruyük \\
C4 & Geminin Çevreye Duyarlılı̆ı & P4 & Ro-Ro \\
C5 & Geminin Bakım Onarım Maliyeti & & \\
C6 & Geminin Satın alma Maliyeti & & \\
C7 & Geminin Taşıma Maliyeti & & \\
\hline
\end{tabular}

Karar noktaları ve seçim kriterleri belirlendikten sonra bunları hiyerarşik perspektifte gösterebilmek için hiyerarşik model aşağıdaki gibi oluşturulmuştur. 


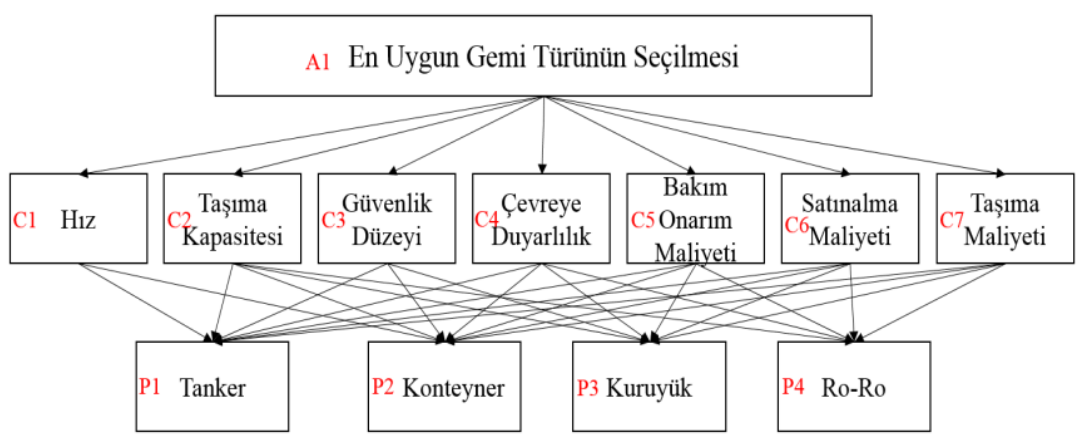

Şekil 2. Gemi türü seçimi için hiyerarşik model

Karar noktalarının ve seçim kriterlerinin belirlenmesi için uzmanlar kurulu üyeleri ile farklı zamanlarda beş kez beyin fırtınası şeklinde gerçekleştirilen yuvarlak masa toplantıları organize edilmiştir.

Adım-2 Karşılaştırma Matrislerinin Oluşturulması: Toplantılar sonucunda belirlenen karar alternatifleri ve seçim kriterleri ile ilgili olarak karar alıcılara yöneltilmek üzere ikili karşılaştırma sorularından oluşan anket hazırlanmış aynı zamanda söz konusu toplantılarda soruların yöneltileceği karar alıcıların profilleri ile karar alıcıların kimler olabileceği saptanmıştır.

Buna göre daha öncede belirtildiği gibi karar alıcılar uzmanlar kurulu üyeleri gibi en az denizcilik sektörü içerisinde üst düzey yönetici olarak veya şirket sahibi olarak yer almış profesyoneller olarak belirlenmiş, şirket ve isim olarak tanımlanmışlardır. Bu kapsamda kırk denizcilik işletmesinin sahibi ya da üst düzey yöneticisi olan profesyoneller karar alıcılar olarak seçilmiştir.

Bu konuda bir diğer önemli kriter ise gemi satın alınması ile ilgili karar alma süreçlerinde bu profesyonellerin bulunuyor olmalarıdır. Hazırlanan ikili karşılaştırma soruları karar alıcılara yöneltilmiş, her bir karşılaştırma için verilen cevaplar ile ilgili olarak aritmetik ortalama alınarak, seçim kriterlerine ilişkin karar matrisinin elemanlarının sayısal değerleri hesaplanmıştır.

$$
A=\left[\begin{array}{rrrrrrr}
1,00 & 0,54 & 0,40 & 0,39 & 0,28 & 0,31 & 0,30 \\
1,84 & 1,00 & 0,70 & 0,82 & 1,60 & 1,74 & 0,49 \\
2,50 & 1,43 & 1,00 & 1,00 & 1,55 & 2,23 & 1,64 \\
2,55 & 1,23 & 1,00 & 1,00 & 3,96 & 0,73 & 1,81 \\
3,54 & 0,62 & 0,64 & 0,25 & 1,00 & 1,09 & 1,03 \\
3,22 & 0,58 & 0,45 & 1,38 & 0,92 & 1,00 & 3,09 \\
3,32 & 2,03 & 0,61 & 0,55 & 0,97 & 0,32 & 1,00
\end{array}\right]
$$

Karar matrisi ya da karşılaştırma matrisi olarak adlandırılan matris A oluşturulurken, her bir sütun toplamı da hesaplanmıştır.

Adım-3 Faktörlerin Önem Dağılımlarının Belirlenmesi: Üçüncü aşamada karar matrisinin her bir elemanı kendi sütun toplamına bölünerek normalize matrisi oluşturacak B vektörleri hesaplanmaktadır. Eşitlik 3 kullanılarak bütün matris elemanları normalize edilmiş ve karşılaştırma yapmaya olanak verecek şekilde normalize matrisin eleman değerleri hesaplanmıştır. Buna bağlı olarak elde edilen B vektörlerinin toplamı olarak aşağıda gösterilen normalize matris $\mathrm{C}$ ye ulaşılabilmektedir. 


\begin{tabular}{|c|c|c|c|c|c|c|c|}
\hline & {$[0,0556$} & 0,0730 & 0,0833 & 0,0727 & 0,0274 & 0,0419 & 0,0321 \\
\hline & 0,1025 & 0,1346 & 0,1459 & 0,1513 & 0,1557 & 0,2344 & 0,0525 \\
\hline & 0,1391 & 0,1922 & 0,2084 & 0,1858 & 0,1511 & 0,3005 & 0,1752 \\
\hline$C=$ & 0,1419 & 0,1649 & 0,2080 & 0,1854 & 0,3853 & 0,0978 & 0,1929 \\
\hline & 0,1971 & 0,0840 & 0,1340 & 0,0468 & 0,0972 & 0,1471 & 0,1104 \\
\hline & 0,1790 & 0,0774 & 0,0935 & 0,2555 & 0,0891 & 0,1348 & 0,3302 \\
\hline & {$[0,1849$} & 0,2738 & 0,1270 & 0,1026 & 0,0941 & 0,0436 & 0,1068 \\
\hline$\sum$ & 1,0000 & 1,0000 & 1,0000 & 1,0000 & 1,0000 & 1,0000 & 1,0000 \\
\hline
\end{tabular}

Normalizasyon işleminin ardından $C$ matrisinin her satırının ortalaması alınarak, öncelik vektörü olarak nitelendirilen w vektörü oluşturulmaktadır. Vektör w aynı zamanda her bir seçim kriterinin göreli olarak önem değerlerini göstermektedir.

$$
w=\left[\begin{array}{c}
0.0552 \\
0.1395 \\
0.1932 \\
0.1966 \\
0.1167 \\
0.1656 \\
0.1332
\end{array}\right]
$$

Yukarıda gösterilen $w$ vektöründen de anlaşılacağı gibi, geminin çevreye duyarlılığı olarak belirlenen seçim kriteri en yüksek yüzdelik değer olan \%19,66 değerini alırken, geminin güvenlik düzeyi en yüksek ikinci önem derecesine ulaşmaktadır. Diğer seçim kriterleri farklı puanlar alırken, en düşük önem derecesi geminin hızı olarak saptanmaktadır.

Adım-4 Tutarlılık Analizi: Tutarlılık analizi yapabilmek üzere öncelikle D matrisi oluşturulmuştur. D matrisi; karar matrisi ile w vektör değerlerinin çarpılması sonucunda elde edilmektedir. A matrisinin her bir satırı w vektörünün değerleri ile çarpıldıktan sonra elde edilen değer w vektörünün satır değerine bölünerek $\mathrm{E}$ değerlerine ulaşılmaktadır.

$$
E=\left[\begin{array}{c}
7,4276 \\
7,7196 \\
7,7476 \\
7,7537 \\
7,6429 \\
7,8485 \\
7,4560
\end{array}\right]
$$

E değerleri hesaplandıktan sonra, $\lambda_{\text {mak }}$ değeri eşitlik 10 kullanılarak hesaplanmıştır. Buna göre $\lambda_{\text {mak }}$ değeri aşağıda gösterilmektedir.

$$
\lambda_{\text {mak }}=\frac{\sum_{i=1}^{n} E_{i}}{n} \Rightarrow \frac{53,60}{7}=7,6566
$$

$\mathrm{Bu}$ işlemin ardından tutarlılık indeksi CI değeri eşitlik 11 kullanılarak hesaplanmış, sonuç olarak aşağıdaki değere ulaşılmıştır.

$$
C I=\frac{\lambda_{m a k}-n}{n-1} \Rightarrow \frac{7,6566-7}{7-1}=0,1094
$$

Eşitlik 12 kullanılarak, tutarlılık indeks değeri (CI) Random indeks (RI) tablosundan elde edilen 1,32 değerine bölündüğünde tutarlılık oranı CR değerine ulaşılabilmektedir.

$$
C R=\frac{C I}{R I} \Rightarrow \frac{0,1094}{1,32}=0,083
$$

Yukarıda görüldüğg̈ gibi tutarlılık değeri 0,083 olarak hesaplanmış, 0,10 değerinden daha düşük olduğu için değerlendirme tutarlı olarak kabul edilebilmekte, çalışmanın bir sonraki aşamasına geçilebilmektedir. 
Adım-5 Faktörlerin Önem Değerinin Hesaplanması: Seçim kriterleri için gerçekleştirilen ilk dört aşamada uygulanan yöntemler karar alternatifleri için aynı şekilde uygulanmış, karar alternatifleri için her bir seçim kriteri çerçevesinde ikili karşılaştırma matrisleri oluşturulmuştur.

C1 Geminin Hzz

$A_{1}=\begin{array}{rrrrl}\text { P1 } 1 \\ \text { P2 } \\ \text { P3 }\end{array}\left[\begin{array}{cccc}1,00 & \text { P2 } & \text { P3 } & \text { P4 } \\ 1,44 & 1.00 & 1,30 & 2,66 \\ 0,44 & 0,65 & 1.00 & 3,88 \\ 0,38 & 0,35 & 0,31 & 1.00\end{array}\right]$

$\mathrm{C}_{4}$ Geminin Çevreye Duyarlılığı

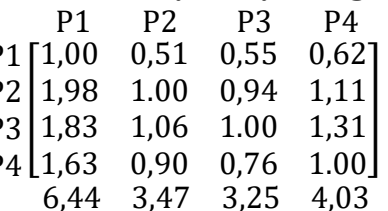

$\begin{array}{llll}\mathbf{C}_{7} & \begin{array}{rrr}6,44 \\ \text { Geminin Taşıma Maliyeti }\end{array}\end{array}$

$$
A_{7}=\begin{array}{rrrr}
\mathrm{P} 1 \\
\mathrm{P} 2
\end{array}\left[\begin{array}{cccc}
1,00 & 1,55 & 1,62 & 0,89 \\
0,65 & 1.00 & 3,09 & 1,64 \\
0,62 & 0,32 & 1.00 & 1,39 \\
1,12 & 0,61 & 0,72 & 1.00
\end{array}\right]
$$

\begin{tabular}{|c|c|c|c|c|}
\hline & P1 & $\mathrm{P} 2$ & P3 & P4 \\
\hline & P1 $[1,00$ & 1,62 & 1,84 & $1,69]$ \\
\hline & P2 0,62 & 1.00 & 2,97 & 2,29 \\
\hline & P3 0,59 & 0,34 & 1.00 & 1,04 \\
\hline & P4 $[2,75$ & 0,44 & 0,96 & 1.00 \\
\hline & 4,96 & 3,39 & 6,77 & 6,01 \\
\hline
\end{tabular}

\section{$\mathrm{C}_{2}$ Geminin Taşıma Kapasitesi}

C5 Gemi Bakım Onarım Maliyeti

$\left.A_{5}=\begin{array}{ccccc}P 1 & P 1 & P 2 & P 3 & P 4 \\ P 3 & P 3 & 1,17 & 0,86 & 0,68 \\ 0,85 & 1.00 & 1,02 & 1,14 \\ 1,17 & 0,98 & 1.00 & 1,27 \\ 1,48 & 0,88 & 0,78 & 1.00\end{array}\right]$

\section{C3 Geminin Güvenlik Düzeyi}

$$
\begin{aligned}
& \begin{array}{llll}
\mathrm{P} 1 & \mathrm{P} 2 & \mathrm{P} 3 & \mathrm{P} 4
\end{array} \\
& \mathrm{P} 1\left[\begin{array}{llll}
1,00 & 0,64 & 0,50 & 0,55
\end{array}\right. \\
& A_{3}=\begin{array}{lllll}
\mathrm{P} 2 & 1,56 & 1.00 & 0,65 & 0,71 \\
\mathrm{P} 3 & 2,00 & 1,54 & 1.00 & 0,68
\end{array} \\
& \mathrm{P} 4\left[\begin{array}{llll}
1,82 & 1,40 & 3,63 & 1.00
\end{array}\right] \\
& \begin{array}{lllll}
\Sigma & 6,38 & 4,58 & 3,63 & 2,94
\end{array}
\end{aligned}
$$

\section{C6 Geminin Satınalma Maliyeti}

$$
\begin{aligned}
& \begin{array}{llll}
\mathrm{P} 1 & \mathrm{P} 2 & \mathrm{P} 3 & \mathrm{P} 4
\end{array} \\
& A_{6}=\begin{array}{l}
P 1 \\
P 2 \\
P 3
\end{array}\left[\begin{array}{llll}
1,00 & 4,06 & 3,41 & 2,19 \\
0,25 & 1.00 & 0,60 & 0,57 \\
0,29 & 1,66 & 1.00 & 0,85 \\
0,46 & 1,76 & 1,18 & 1.00
\end{array}\right] \\
& P 4\left[\begin{array}{llll}
0,46 & 1,76 & 1,18 & 1.00
\end{array}\right] \\
& \begin{array}{lllll}
\Sigma & 2,00 & 8,48 & 6,19 & 4,60
\end{array}
\end{aligned}
$$

İkili karşılaştırma matrisleri olarak tanımlanan A matrisleri oluşturulduktan sonra, her bir

\begin{tabular}{|c|c|c|c|c|}
\hline P1 & P2 & P3 & P4 & \\
\hline $1[0,2222$ & 0,2906 & 0,2343 & & \\
\hline \begin{tabular}{l|l} 
P2 & 0,1895
\end{tabular} & 0,2478 & 0,2777 & 0,2785 & \\
\hline \begin{tabular}{l|l}
3 & 0,2594
\end{tabular} & 0,2440 & 0,2735 & 0,3117 & \\
\hline P4 [0,3289 & 0,2176 & 0,2145 & 0,2 & \\
\hline & 10 & 1,00 & 10 & \\
\hline
\end{tabular}
matrisin elemanları sütun değerlerinin toplamına bölünerek bütün karar matrisleri normalize edilmiş, bir sonraki adımda normalize matrislerin satır değerlerinin aritmetik ortalamaları

\begin{tabular}{|c|c|c|c|c|}
\hline P1 & P2 & P3 & P4 & S1 \\
\hline $1[0,5$ & 0,4788 & 0,5509 & & \\
\hline 0,1234 & 0,1179 & 0,0972 & & \\
\hline \begin{tabular}{l|l} 
P3 & 0,1468
\end{tabular} & 0,19 & 0,16 & & \\
\hline P4[0,2289 & 0,2074 & 0,19 & 0,2172 & \\
\hline & & & 1,00 & \\
\hline
\end{tabular}
alınarak $\mathrm{S}$ vektörleri elde edilmiştir.

\begin{tabular}{|c|c|c|c|c|c|}
\hline & P1 & $\begin{array}{c}\mathrm{P} 2 \\
0,4452\end{array}$ & $\begin{array}{c}\text { P3 } \\
0,2520\end{array}$ & $\begin{array}{c}\text { P4 } \\
0,1813\end{array}$ & S1 \\
\hline & 0,1908 & 0,2872 & 0,4804 & & \\
\hline & 0,182 & 0,0930 & & & \\
\hline & & & & & \\
\hline & 1,0 & 1,00 & 100 & 1,00 & 10 \\
\hline
\end{tabular}

$$
\begin{aligned}
& C_{1} \text { Geminin Hızı }
\end{aligned}
$$

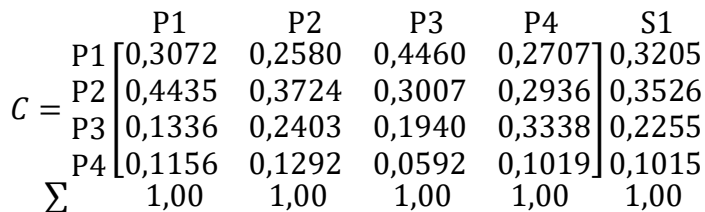

$$
\begin{aligned}
& \mathrm{C}_{2} \text { Geminin Taşıma Kapasitesi }
\end{aligned}
$$

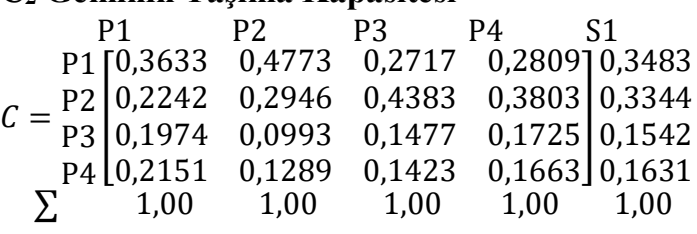

\section{$C_{3}$ Geminin Güvenlik Düzeyi}

$$
\begin{aligned}
& \begin{array}{lllll}
\text { P1 } & \text { P2 } & \text { P3 } & \text { P4 } & \text { S1 }
\end{array} \\
& \text { P1 [ [ }\left[\begin{array}{llll}
0,1566 & 0,1399 & 0,1376 & 0,1870] 0,1553
\end{array}\right. \\
& \begin{array}{l|llll|l}
\mathrm{P} 2 & 0,2445 & 0,2183 & 0,1793 & 0,2426 & 0,2212 \\
\mathrm{P} 3 & 0,3135 & 0,3353 & 0,2753 & 0,2299 & 0,2885
\end{array} \\
& \text { P4 }\left[\begin{array}{llll}
0,2853 & 0,3056 & 0,4078 & 0,3405
\end{array}\right] 0,3351 \\
& \begin{array}{llllll}
\Sigma & 1,00 & 1,00 & 1,00 & 1,00 & 1,00
\end{array}
\end{aligned}
$$$$
\mathrm{C}_{4} \text { Geminin Çevreye Duyarlılığı }
$$

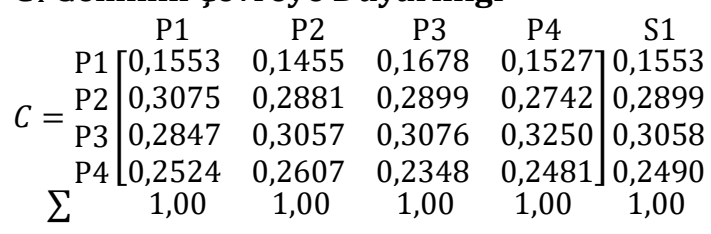

\section{C5 Geminin Bakım Onarım Maliyeti}

$\mathrm{C}_{6}$ Geminin Satınalma Maliyeti

\section{$\mathrm{C}_{7}$ Geminin Taşıma Maliyeti}


İşlemlerin ardından $\mathrm{K}$ matrisinin oluşturulması için bir araya getirilecek bütün $\mathrm{S}$ vektörleri elde edilmiştir. Hemen ardından dördüncü aşamada gösterilen işlemler kullanılarak karar noktaları için gerçekleştirilen değerlendirmelerin tutarlılıkları analiz edilmiş, bütün faktör kıyaslamalarının tutarlılıkları sırasıyla 0,038; 0,012; 0,001; 0,019; 0,005; 0,096 olarak hesaplanmıştır. Dolayısıyla bütün ikili kıyaslamaların tutarlık değerleri 0,10 'un altında olduğundan değerlendirmeler tutarlı olarak kabul edilebilmektedir. Bu işlemlerin ardından Analitik Hiyerarşi Prosesi yönteminin altıncı ve son aşamasına geçilmiştir.

Adım-6 Sonuç Dağılımlarının Belirlenmesi: Son aşamada bütün S vektörleri bir araya getirilmiş ve $\mathrm{K}$ matrisi elde edilmiştir.

$$
K=\left[\begin{array}{lllllll}
0,3205 & 0,3483 & 0,1553 & 0,1553 & 0,2281 & 0,5014 & 0,2935 \\
0,3526 & 0,3344 & 0,2212 & 0,2899 & 0,2484 & 0,1155 & 0,3231 \\
0,2255 & 0,1542 & 0,2885 & 0,3058 & 0,2722 & 0,1721 & 0,1782 \\
0,1015 & 0,1631 & 0,3351 & 0,2490 & 0,2514 & 0,2110 & 0,2052
\end{array}\right]
$$

Bir sonraki aşamada $\mathrm{K}$ matris değerleri seçim kriterlerinin önem değerleri hesaplanırken elde edilen w vektörünün elemanları ile çarpılarak, L vektörü elde edilmektedir.

$$
\begin{aligned}
& K=\left[\begin{array}{lllllll}
0,3205 & 0,3483 & 0,1553 & 0,1553 & 0,2281 & 0,5014 & 0,2935 \\
0,3526 & 0,3344 & 0,2212 & 0,2899 & 0,2484 & 0,1155 & 0,3231 \\
0,2255 & 0,1542 & 0,2885 & 0,3058 & 0,2722 & 0,1721 & 0,1782 \\
0,1015 & 0,1631 & 0,3351 & 0,2490 & 0,2514 & 0,2110 & 0,2052
\end{array}\right] \times\left[\begin{array}{l}
0,0552 \\
0,1395 \\
0,1932 \\
0,1966 \\
0,1167 \\
0,1656 \\
0,1332
\end{array}\right] \\
& L=\begin{array}{ll}
\text { P1 } & \text { Tanker Gemiler } \\
\text { P3 } & \text { Konteyner Gemileri } \\
\text { P4 } & \text { Ro }- \text { Ro Gemiler Gemiler }
\end{array}\left[\begin{array}{l}
0,2756 \\
0,2570 \\
0,2338 \\
0,2337
\end{array}\right]
\end{aligned}
$$

\section{Tartışma, Sonuç ve Öneriler}

Lojistik ve tedarik zinciri yönetimi açısından denizyolu taşımacılı̆̆ında kullanılacak gemilerin seçilmesi son derece önemli bir konudur. Gemi türü seçimi bir tedarik zincirinin bütünü etkileyen ve operasyonların başarısına doğrudan etkilere sahip olan son derece kritik bir karardır. Gerçekleştirilecek satın alma sürecinde yapılacak hataların geri dönüşü zor hatta imkânsız olabilmektedir. Gemi türü seçimi çok fazla sayıda faktör tarafından etkilenen bir seçim süreci olduğu için, problemin optimal düzlemde çözümü çok kriterli karar alma yöntemleri kullanılarak mümkün olabilmektedir.

$\mathrm{Bu}$ çalışmada gemi türü seçimi ile ilgili olarak, çok kriterli karar verme yöntemlerinden birisi olan Analitik Hiyerarşi Prosesi yöntemi seçilmiş, yöntemin adımları uygulanarak, gemi türü seçimine etki eden kriterlerin ve karar noktalarının yanı sıra bunların göreli önem değerleri sayısal bir ölçekte belirlenmiştir. Dolayısıyla bu çalışma denizcilik işletmelerinin gemi yatırımında bulunacakları zaman tercih edecekleri gemi tiplerine ilişkin karar alma süreçleri ile ilgili olarak tutumlarına etki eden faktörleri değerlendirebilmek için metodolojik bir çerçeve ortaya koymaktadır.

Elde edilen sonuçlar değerlendirildiğinde, denizcilik işletmelerinin gemi türü tercihi ile ilgili karar alma süreçlerinde bulunan uzmanların geminin çevreye olan duyarlılığını \%19,66 ile en yüksek düzeyde önemsedikleri, bunu \%19,33 değeri ile geminin güvenlik düzeyinin izlediği 
görülmektedir. Geminin satın alma maliyeti ise \%16,56 değeri ile üçüncü sırada yer almaktadır. Nihai olarak bakıldığında, karar alternatifleri arasında yer alan tanker, konteyner, kuruyük ve Ro-Ro gemileri değerlendirildiğinde seçim kriterlerine en optimal düzeyde cevap veren gemi türü olarak \%27,56 ile en yüksek düzeyde tercih edilen gemi türü tanker gemiler olarak belirlenmiştir. Bunu \%25,70 ile konteyner gemileri izlemekte, kuruyük ve Ro-Ro gemileri birbirine çok yakın değerler alarak en düşük tercih edilebilir gemiler olarak değerlendirilebilmektedir.

Özellikle gemi türü seçimi ile ilgili dikkate alınması gereken kriterler ile karar alternatiflerinin belirlenmesi ve her bir faktör için göreli önem derecelerinin hesaplanması matematiksel bir model olarak AHP yönteminin uygulanmasını, bu sayede elde edilecek sonuçların daha rasyonel ve optimal olabilmesini mümkün hale getirebilecektir.

Daha da önemlisi AHP yönteminin karar vericilerin sözel yargılarını ölçülebilir ve kıyaslanabilir verilere dönüştürebilmesiyle söz konusu yargıların karar alma sürecine dahil edilebilmesi olanaklı olacak, böylelikle söz konusu yöntem karar alıcılara kolayca uygulayabilecekleri sistematik ve yapısal bir çerçeve sağlayabilecektir. Bu çalışmada elde edilen sonuçlar denizyolu taşımacılığı ile ilgili tüm taraflara gemi türü seçimi ile ilgili karar verme süreci ile ilgili bilgi ve bir uygulama çerçevesi oluşturabilir. Öte yandan gemi türlerine ilişkin seçim süreçlerinin AHP yöntemi ile değerlendirilmesi denizcilik alanında görev yapan karar alıcıların uygulamaya ilişkin yaklaşımlarının bilimsel bir perspektifte aktarılabilmesine olanak sağlamış, aynı zamanda teorik ve pratik uygulamaların etkileşimine katkı sağlamıştır.

\section{Teşekkür}

$\mathrm{Bu}$ çalışmaya uzmanlar kurulu üyesi olarak katılan tüm uzman yöneticilere, mesleki kuruluşlara ve temsilcilerine, çalışmada karar alıcı olarak iştirak ederek gemi türü seçimi ile ilgili görüşlerini paylaşan lojistik ve denizcilik işletmelerinin yönetici ve sahiplerine içtenlikle teşekkür ederiz.

\section{Kaynakça}

Alonso, J. A. (2006). Consistency in the Analytic Hierarchy Process: A New Approach. International Journal of Uncertainty, Fuzziness and Knowledge-Based Systems, 14, 445-459.

Cedolin, M., \& Sener, Z. An integrated fuzzy decision approach for selecting ships in maritime logistics. XIV. International Logistics and Supply Chain Congress, December 01-02, 2016, Izmir, TURKIYE

Finan, J., \& Hurley, W. (1999). Transitive Calibration of the AHP Verbal Scale. European Journal of Operational Research, 112, 367-372.

Insignares E., Verma B., \& Fuentes D. (2020). Evaluation methodology for the selection of the combined propulsion system for an offshore patrol vessel (OPV93C). Proceeding of the VI International Ship Design \& Naval Engineering Congress (CIDIN) and XXVI Pan-American Congress of Naval Engineering, Maritime Transportation and Port Engineering. CIDIN 2019, COPINAVAL 2019. Springer, Cham. 
Kovačić, M., \& Mrvica, A. (2017). Selecting the size and type of a vessel for the purpose of maritime connection of mainland and islands and between the islands in Croatia, XLIV Symposium on Operational Research, Zlatibor, 25-28 Eylül.

Kundakcı, N., Adalı, E. A., \& Işık, A. T. (2014). Combination of DEMATEL and ANP for the cargo shipping company selection problem. International Journal of Engineering Management and Economics, 4(2) 99-116.

Luo, M. (2010). Determinants of container ship investment decision and ship choice. International Forum On Shipping. Ports and Airports (IFSPA) 2010 - Integrated Transportation Logistics: From Low Cost to High Responsibility Congress, 10-18 October, Chengdu Sichuan, 449-462.

Myers, J., \& Alpert, M. (1968). Determinant buying attributes: meaning and measurement. Marketing, 2, 13-20.

Saaty, T. (1977). A Scaling Method for Priorities in Hierarchical Structures. Journal of Mathematical Psychology, 15, 234-281.

Saaty, T. (1980), The Analytic Hierarchy Process, McGraw-Hill, New York, NY.

Sener, Z., (2016). Evaluating ship selection criteria for maritime transportation. Journal of Advanced Management Science, 4(4), 325-328.

Sener, Z., \& Ece Ozturk, (2015). A QFD-Based decision model for ship selection in maritime transportation. International Journal of Innovation, Management and Technology, 6(3), 202-205.

Taşkın, A., \& Eren, T. (2016). UEFA Şampiyonlar Ligi'nde forvet oyuncularının performanslarının çok ölçütlü karar verme yöntemleri ile değerlendirilmesi. Manisa Celal Bayar Üniversitesi Sosyal Bilimler Dergisi, 14(1), 79-105.

Uğurlu, Ö., (2015). Application of Fuzzy Extended AHP methodology for selection of ideal ship for oceangoing watchkeeping officers. International Journal of Industrial Ergonomics, 47, 132-140.

Xie, X., Xu, D., Yang, J., Wang, J., Ren, J., \& Yu, S. (2008). Ship selection using a multiple-criteria synthesis approach. Journal Marine Science Technology, 13, 50-62

Yang, Z. L., Bonsall, S., \& Wang, J. (2011). Approximate TOPSIS for vessel selection under uncertain environment. Expert Systems with Applications, 38(12), 14523-14534.

Yang, Z. L., Mastralis, L., Bonsall, S., \& Wang, J. (2009). Incorporating uncertainty and multiple criteria in vessel selection. Proceedings of the Institution of Mechanical Engineers, Part M: Journal of Engineering for the Maritime Environment, 223(2), 177-188.

Yang, Z. L., Mastralis, L., Bonsall, S., \& Wang, J. (2018) Use of fuzzy evidential reasoning for vessel selection under uncertainty. In: Lee PW., Yang Z. (eds) Multi-Criteria Decision Making in Maritime Studies and Logistics. International Series in Operations Research \& Management Science, 260. Springer, Cham, 105-121. 